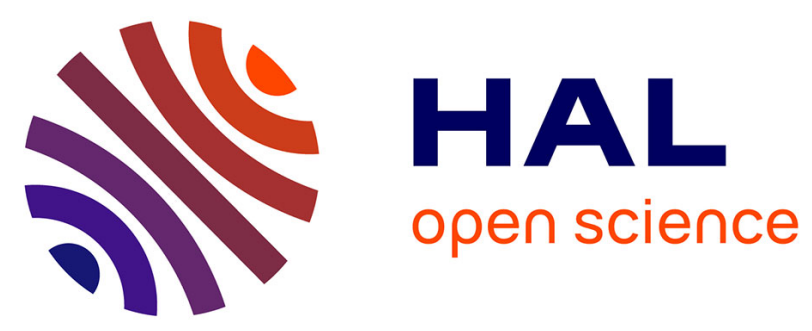

\title{
A COMPACT, DIFFRACTION LIMITED, He FREE, HIGH REPETITION FREQUENCY NANOSECOND CO2 LASER
}

\author{
S. Marchetti, S. Bartalini, M. Giorgi, R. Simili
}

\section{- To cite this version:}

S. Marchetti, S. Bartalini, M. Giorgi, R. Simili. A COMPACT, DIFFRACTION LIMITED, He FREE, HIGH REPETITION FREQUENCY NANOSECOND CO2 LASER. Journal de Physique IV Proceedings, 1991, 01 (C7), pp.C7-765-C7-767. 10.1051/jp4:19917205 . jpa-00250886

\section{HAL Id: jpa-00250886 https://hal.science/jpa-00250886}

Submitted on 1 Jan 1991

HAL is a multi-disciplinary open access archive for the deposit and dissemination of scientific research documents, whether they are published or not. The documents may come from teaching and research institutions in France or abroad, or from public or private research centers.
L'archive ouverte pluridisciplinaire HAL, est destinée au dépôt et à la diffusion de documents scientifiques de niveau recherche, publiés ou non, émanant des établissements d'enseignement et de recherche français ou étrangers, des laboratoires publics ou privés. 


\title{
A COMPACT, DIFFRACTION LIMITED, He FREE, HIGH REPETITION FREQUENCY NANOSECOND $\mathrm{CO}_{2}$ LASER
}

\author{
S. MARCHETTI, S. BARTALINI, M. GIORGI and R. SIMILI \\ IFAM-CNR, Via del Giardino 7, I-56100 Pisa, Italy
}

\begin{abstract}
A compact He free $\mathrm{CO}_{2}$ laser is briefly described. This laser can operate at $10 \mathrm{~Hz}$ with $150 \mathrm{~mJ}(12 \mathrm{~ns})$, without tail at its diffraction limit (1.5mrad) and it can be used in LIDAR experiments with few meter spatial resolution.
\end{abstract}

\section{1:INTRODUCTION}

The LIDAR experiments need a typical laser source with $0.1-1 \mathrm{~J}$ fluence, more than $10 \mathrm{~Hz}$ repetition frequency, $10 \mathrm{~ns}$ laser pulse, at $1 \mathrm{mrad}$ diffraction or less. By using a similar source it is possible to detect an echo signal $10 \mathrm{Km}$ away with meter resolution.. Normally a $\mathrm{CO}_{2}$ laser has

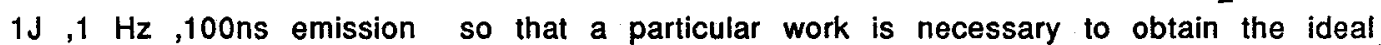
characteristics. In particular a tail free short pulse can be obtained only in He free mixtures at few bar pressure in a short, high gain device, so that a particular discharge design must be used to stabilize a multiatmosphere $\mathrm{CO}_{2}$ dominated high energy density discharge. Besides these problems limit the electrode distance, so that a suitable optical design is necessary to obtain a short pulse diffraction limited emission without optical damage.

\section{2: EXPERIMENT AND RESULTS}

To obtain a laser discharge with elevate pressure and energy density, and with moderate specific electric field $E$, we have used a double tension symmetrical Blumlein LC inverter (1-2) . In this case a fast low inductive discharge is produced. The discharge design is reported in fig $1.8 \mathrm{C}_{1}$ banks are discharged in four preionization spark lines (the design shows only four $C_{1}$ banks and two $P$ preinizations for clarity) in the time (100ns) of the LC inversion polarity relatively to four $\mathrm{C}^{\star}$ banks $\left(\mathrm{C}^{*}=\mathrm{C}\right)$ by means of a single sparg gap SG. This inversion and the use of opposite polarity for one half of banks allow to apply a $4 \mathrm{~V}$ peak voltage to the electrodes $E$ allowing a fast energetic discharge in a strongly preionized mixture. Typical 1000J/l energy deposition can be obtained with $V=20 \mathrm{KV}$. A 2bar discharge with $2 \mathrm{~d}=8 \mathrm{~mm}$ electrode distance can be obtained with $80 \mathrm{KV}$ peak voltage in the standard $\mathrm{CO}_{2}: \mathrm{N}_{2}=1: 1 \mathrm{He}$ free mixture. Now it has been reported previously (3) that with a suitable cavity design a tail free emission in 10ns time it is possible in a similar device with $30 \mathrm{~J} / \mathrm{lt}$ fluence extraction which is a damage limit for the optical components.

By using a longer device with moderate power density( $700 \mathrm{~J} / \mathrm{lt}$ ) it is possible to obtain the same results without optical damage if a $60-80 \%$ typical outcoupling transmission is used. In this case it is possible to use an unstable configuration to obtain a diffraction limited emission .In our case a $8 \mathrm{~mm}$ discharge can give a full divergence (FWHM)

$$
2 \Theta(F W H M)=1.22 \lambda(2 d)=1.5 \mathrm{mrad}
$$

but due to the collimation, which is necessary to avoid the transverse modes, the divergence with 


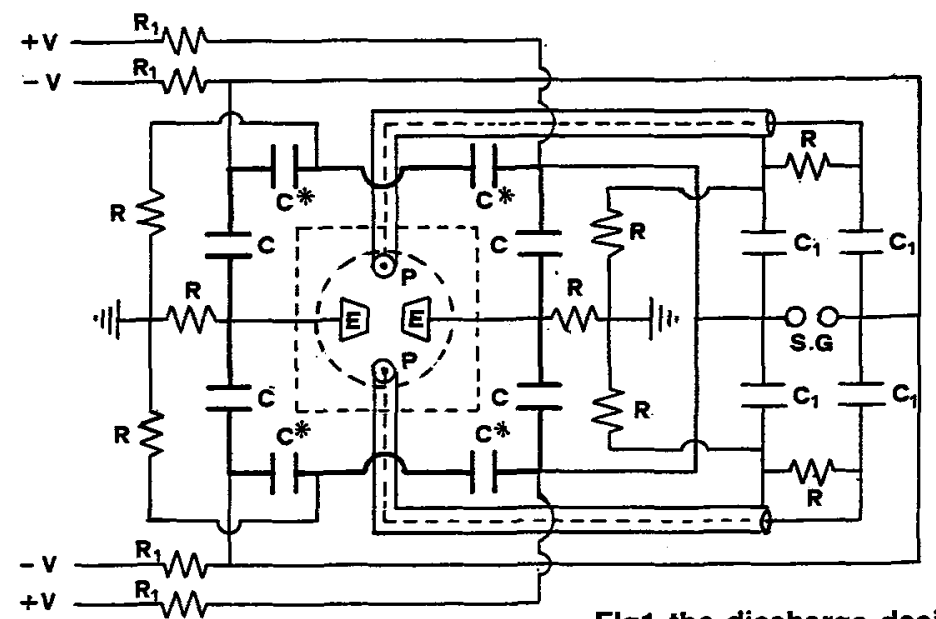

Flg1 the discharge design (see text)

a stable cavity is two times larger. So we need an ustable cavity very short. The optical design is reported in fig 2. A plane mirror $M 1$ is $45^{\circ}$ rotated respect to the optical axis and it has a $2 a$ $=3.6 \mathrm{~mm}$ hole. The $\mathrm{M} 2$ mirror reflects the transmitted power to the grating $\mathrm{G}$. The amplified and diffracted beam is splitted by $M 1$ so that a circular ring with $70 \%$ of the total power is ejected out of the cavity to M3 with $4 \mathrm{mt}$ curvature radius posed in a suitable distance ( $1 \mathrm{mt}$ from M1) where the beam is collimated to obtain the theoretical divergence. The cavity lenght $L$ is 70 $\mathrm{cm}$ and the $L$ and a values are chosen to fully cover the discharge section with an approximated $70 \%$ outcoupling. The emitted power is roughly an overlap of two field distributions with two diffent confocal parameters $b_{0}=\pi d^{2} / \lambda$ and $b_{1}=\pi a^{2} / \lambda$ where $b_{0}>b_{1}$ so that when the distance $D$ from $M 1$ is >> b1 we have only the first component inside the laser spot with a power loss $\cong(a / d)^{2}$ $\cong 0.25$, and a like gaussian spot for $D>b_{0}$ (far field) where in the near field $\left(D<b_{0}\right)$ we have all the power with an interfered spot.

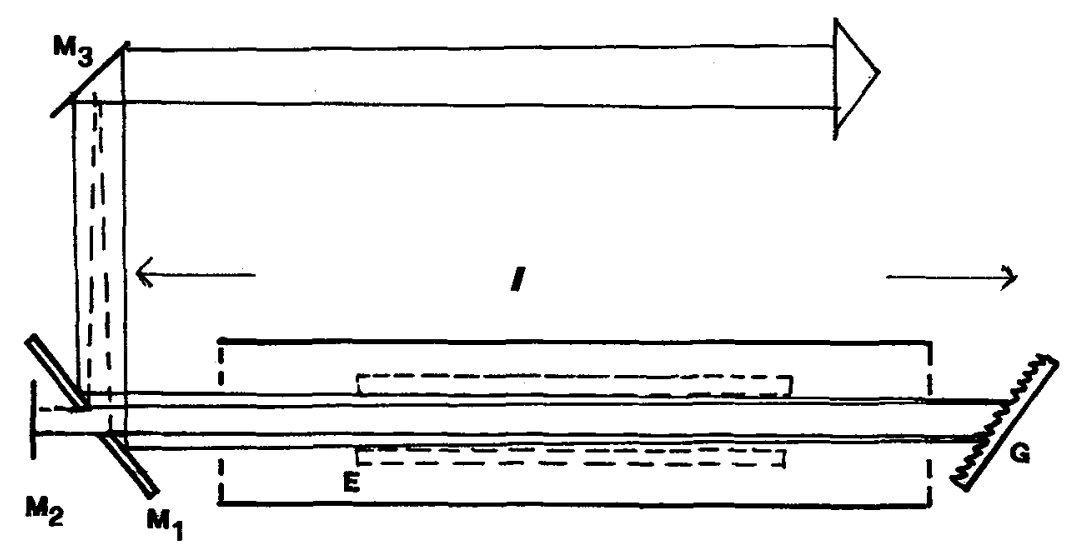

Flg 2 the cavity design(see text)

The spot diameter and the total power inside it vs. the distance D from the M1 mirror, is reported in fig 3 . The fluence is directly measured by focusing the power in a large pyroelectric and the spot is detected by a graphite plate in the near field, while in the far field it is relatively 


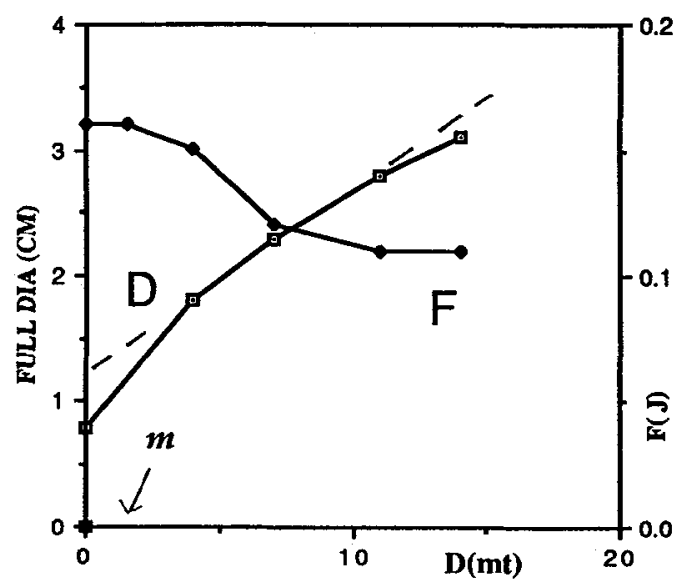

FIG 3 : The fluence $F$ and the diameter vs. the distance $D$

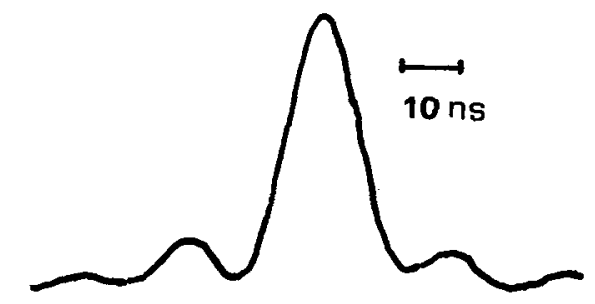

FIG 4: The laser pulse

measured by means of a small section pyroelectric .M points to the M3 mirror position.The divergence in the far field (linear fit) is near $1.5 \mathrm{mrad}$ while the estimated fluence inside the spot goes down from $160 \mathrm{~mJ}$ to $110 \mathrm{mj}$ about (30\% reduction) near the expected value. The spot for distances larger than 10 meters is like -gaussian. The time profile for this diffraction limited pulse is measured focusing it in a Photon-drag . The relative pulse is reported in fig 4., where a like gaussian pulse is detected. The shape is Fourier transform limited to the time resolution of our digital oscilloscope,as shown by the side modulation, and a 12 ns pulse width can be extimated. To increase the repetition frequency it is necessary to increase the gas flow. The maximum possible rate is PPS $=F /\left(V_{0} P\right.$ ), where $F$ is the flow (liter/sec (TPS)) and $V_{0}$ is the discharge volume(liters) and $P$ the operating pressure(atm). Normally the effective limit is 2 times lower due to occasional arcing. For exemple with $F=0.3 \mathrm{lit} / \mathrm{sec}$ and $V_{0}=.02 \mathrm{lt}$. and $P=2 \mathrm{bar}$ we have obtained a linear mean power increase up to $7 \mathrm{~Hz}$. The He free mixture is very cheap, so that the laser running cost at this flow is very low.

\section{3: CONCLUSIONS}

A tail free, unstable, $\mathrm{He}$ free, multiatmospheric $\mathrm{CO}_{2}$ laser is briefly described. About $110 \mathrm{mj}$ (12ns) in the diffraction limit (1.5mrad) are observed in a far field gaussian spot. A low cost $10 \mathrm{~Hz}$ operation is possible without any gas circulation. This laser is ideal for high resolution LIDAR experiments.

\section{4: REFERENCES}

1) G.C. Stuart,H. Houtman,J.Meyer: Rev.Sci Instrum.58,161,(1987)

2)S. Marchetti, R, Simili: Opt. \& Laser Techn. 23, 31 (1991)

3)S. Marchetti, R. Simili: ECOOSA conf Dig., 71 ,Roma, Nov 1990 ,also to be publish

*) work supported by progetto finalizzato tecnologie elettroottiche del CNR

+) ENEA DIP TIB FRASCATI 